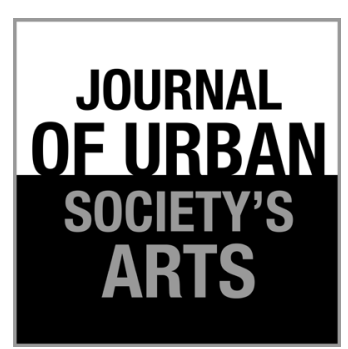

Volume 4 Nomor 1 , April 2017: 11-18

\section{Kapital dan Strategi Garin Nugroho dalam Proses Produksi Film}

Vedy Santoso

Pengkajian Seni Videografi, Program Pascasarjana Institut Seni Indonesia Yogyakarta Jln. Suryodiningratan No.2, Mantrijeron, Yogyakarta

Tlp.087737760727,E-mail: vedysantos@gmail.com

\begin{abstract}
ABSTRAK
Penelitian ini menganalisis struktur sosial Garin Nugroho sebagai sineas yang dilakukan berdasarkan paradigma sosial-kultural Pierre Bourdieu dengan pendekatan strukturalisme genetik. Teori strukturalisme genetik bertumpu pada empat konsep utama, yakni habitus, arena, kapital, dan strategi. Kajian ini diharapkan dapat melihat realitas sosial seorang sineas ketika memproduksi sebuah film. Data penelitian diperoleh dari dokumentasi media massa, katalog film, hasil wawancara narasumber, dan studi pustaka. Hasil penelitian menunjukkan bahwa terdapat dialektika internalisasi pada habitus Garin Nugroho yang menuntunnya untuk berani menutup luka lama kemudian membuka luka baru pada masa transisi budaya global. Dengan demikian, hubungan antara seni dan teknologi menjadi arena yang dipilih Garin Nugroho dalam memperjuangkan kreativitasnya. Dari arena perjuangan itu, ia memiliki beberapa jenis modal yang dipertukarkan dalam struktur sosialnya. Strategi yang diterapkan Garin Nugroho dalam menghadapi era digital adalah konsisten dalam menggunakan kecanggihan teknologi sebagai alat bantu untuk mewujudkan kreativitas melalui media film.
\end{abstract}

Kata kunci: Garin Nugroho; habitus; arena; kapital; strategi

\begin{abstract}
Capital and Garin Nugroho's Strategy on the Process of Film Production. This study analyzes the social structure of Garin Nugroho as a filmmaker that has been conducted based on the socio-cultural paradigm of Pierre Bourdieu with the genetic structuralism approach. The genetic structuralism theory rests on four main concepts, namely habitus, arena, capital, and strategy. This study is expected to be able to see the social reality of a filmmaker when a film is produced. Data were obtained from the documentation of mass media, film catalogues, informant interviews, and literature. The results of this research show that there is a dialectic of internalization in Garin Nugroho's habitus which leads him to dare to close the old wounds then opens the new ones in the transition period of global culture. Therefore, the relationship between art and technology has been a chosen field by Garin Nugroho in struggling for the creativity. From the field of the struggle, Garin Nugroho has some kind of capitals that are exchanged in the social stucture. The strategy that is applied by Garin Nugroho in facing the digital era is consitent in using the power of technology as a tool to realize any creativity throgh the media of film.
\end{abstract}

Keywords: Garin Nugroho; habitus; arena; capital; strategy 
oleh aktor/aktris berdasarkan kaidah sinematografi. Di sisi lain, film juga dapat disebut sebagai media komunikasi massa yang di dalamnya terdapat nilainilai budaya.

Seorang sineas perlu melakukan beberapa negosiasi terhadap ide, bentuk, dan elemenelemen pendukung lain agar film yang diproduksi mendapat legitimasi karena proses pembuatan film adalah sebuah kerja kolektif seorang sineas bersama krunya. Kru atau pekerja film adalah semua orang yang dipekerjakan dalam pembuatan sebuah film selama hari produksi/syuting, selain para pemain atau aktor/aktris (Tino, 2008: 91). Setidaknya terdapat tiga tahap dalam proses pembuatan film, yaitu proses praproduksi (pembuatan konsep), produksi (syuting/pengambilan gambar), dan pascaproduksi (editing). Setiap kru akan menyumbangkan keahlian masing-masing sesuai dengan terjemahan visi sutradara terhadap skenario. Selain produser dan sutradara, kru inti yang menjadi tulang punggung pembuatan film antara lain manager produksi, asisten sutradara, Director of Photography (DOP), perekam suara, pengarah artistik, dan penyunting atau editor.

Dalam proses produksi film juga dibutuhkan perorangan atau lembaga yang bertindak sebagai pemodal/penyandang dana. Pihak pemodal inilah yang akan membiayai keseluruhan proses produksi hingga film didistribusikan ke masyarakat luas (penonton bioskop/festival film). Tentu pihak pemodal memiliki peran dan kepentingan, maka perhitungan tentang segmentasi penonton menjadi penting dalam proses negosiasi untuk mencapai tujuan masing-masing. Terkait dengan cara pendanaan film, terdapat pula sistem pendanaan dan distribusi film yang bersifat independent, yaitu semua biaya produksi disandang oleh komunitas atau individu yang disebut sebagai film indie (independent film).

Salah satu sineas Indonesia yang berhasil melakukan negosiasi dalam proses perwujudan karyanya adalah Garin Nugroho Riyanto atau yang lebih dikenal dengan Garin Nugroho. Meskipun karya-karya film Garin Nugroho kerap dibayangbayangi oleh stereotipe film yang sukar dipahami oleh penonton, dalam sejarah perfilman Indonesia, Garin Nugroho merupakan salah seorang figur penting yang membangkitkan gelombang baru sinema Indonesia di tengah kesemrawutan sinema Indonesia pasca-1990-an. Setelah film panjang pertamanya, yaitu Cinta dalam Sepotong Roti (1991), film keduanya, Surat untuk Bidadari (1992) berhasil membawa namanya ke panggung festival film internasional. Garin Nugroho mulai dikenal luas. Hingga kini sebagai sineas Garin Nugroho sudah memproduksi puluhan judul film cerita, beberapa film dokumenter, sinetron, dan lain-lain.

Garin Nugroho menyelesaikan pendidikan sekolah menengahnya di Yogyakarta, kemudian meneruskan pendidikan tinggi ke Jakarta di Fakultas Sinematografi, Institut Kesenian Jakarta untuk belajar film (selesai pada 1985). Selain belajar film, Garin Nugroho juga mengikuti pendidikan di Fakultas Hukum, Universitas Indonesia (selesai 1991). Dari sini nampak bahwa secara personal, Garin Nugroho sudah memiliki motivasi individu untuk mempelajari film dan ilmu-ilmu humaniora. Dengan kata lain, sebagai sineas ia diarahkan oleh motivasi ketidaksadaran dari bakat yang dimilikinya, kemudian mempelajari film secara kognitif dengan cara mengaitkan antara kreativitas dan kecerdasan melalui lembaga pendidikan. Hal inilah yang kemudian memosisikan Garin Nugroho sebagai tonggak pertama bagi kelahiran sebuah generasi baru atau dalam wacana perfilaman Indonesia dikenal sebagai "generasi sekolahan".

Garin Nugroho memulai kariernya sebagai kritikus film dan pembuat film dokumenter. Kemudian untuk mengembangkan diri, pada tahun 1987 Garin Nugroho bersama kumpulan kreator audiovisual lulusan Institut Kesenian Jakarta mendirikan komunitas yang bernama Sains Estetika Teknologi (SET) Film Workshop. Awalnya SET Film Workshop adalah sebuah komunitas yang bertujuan untuk menumbuhkan generasi film baru melalui kebebasan ekspresi dan pluralisme penciptaan karya audiovisual serta menjalin kerja sama dengan beragam komunitas untuk menumbuhkan ruang alternatif sebagai momen kreasi dan apresiasi. Namun, seiring dengan perkembangan zaman pada tahun 1999, SET Film Workshop mengembangkan peran sosialnya dengan cara mengubah format lembaga sosial menjadi sebuah yayasan. 
Garin Nugroho banyak menyelesaikan karya filmnya (dokumenter, film pendek dan film panjang) bersama SET Film Workshop. Hingga pada perayaan 250 tahun Mozart, ia terpilih sebagai salah satu dari enam sutradara film inovatif dunia yang kemudian melahirkan karya film eksperimental Opera Jawa (2006). Selain itu, kepedulian Garin Nugroho pada masalah lingkungan hidup tercermin dalam karya filmnya yang berjudul Under The Tree (2008). Film ini berhasil meraih piala citra untuk kategori penyutradaraan terbaik di Festival Film Indonesia 2008.

Berdasarkan uraian di depan nampak bahwa proses produksi film adalah sebuah kerja kolaborasi, dalam artian bahwa inisiatif film mungkin datang dari seorang sineas. Namun dalam proses perwujudanya (prapoduksi, produksi, pascaproduksi) juga melalui proses interaksi sosial. Karya film bukan hanya dibentuk dengan sebuah pemikiran seorang sineas (dalam hal ini pencapaian atau ambisi sineas), melainkan kombinasi dari banyak hal termasuk masyarakat pendukungnya. Dengan demikian, pertanyaan tentang bagaimana strategi yang dilakukan Garin Nugroho sebagai sineas agar mampu bertengger di kancah perfilman nasional dan internasional menjadi menarik untuk dibahas dalam kajian ini. Untuk menjawab pertanyaan tersebut, akan dilakukan analisis struktur sosial dengan menggunakan strukturalisme genetik (Bourdieu, 1990) yang bertumpu pada beberapa konsep utama antara lain: habitus, arena, kapital, dan strategi. Melalui gagasan pemikiran Bourdieu tersebut diharapkan dapat menjembatani antara teori dan tindakan dalam melihat realitas sosial kehidupan Garin Nugroho sebagai seorang sineas. Bourdieu memberikan nama pada orientasi pemikirannya sebagai strukturalisme genetik: analisis struktur-struktur objektif yang tidak bisa dipisahkan dari analisis asal-usul struktur-struktur mental dalam individu-individu biologis yang sebagian merupakan produk penyatuan strukturstruktur sosial itu sendiri (Ritzer \& Goodman J., 2003: 519).

Penelitian menggunakan pendekatan strukturalisme genetik Bourdieu terhadap seniman pernah dilakukan oleh beberapa peneliti terdahulu, antara lain Prasetya, dkk (2012) dan Laksono, dkk
(2015). Prasetya, dkk meneliti habitus seniman tradisi, sedangkan Laksono, dkk meneliti habitus seniman music hip hob. Berbeda dengan kedua peneliti yang lebih menekankan habitus, penelitian yang saya lakukan pada Seniman Garin Nugroho ini lebih menekankan pada kapital dan strategi.

Data penelitian ini diperoleh dari pencarian dokumentasi media massa baik cetak maupun elektronik, dokumentasi dari katalog film, wawancara narasumber, dan studi pustaka. Langkah pertama, saya menggunakan konsep habitus untuk menggambarkan serangkaian kecenderungan yang mendorong pelaku sosial atau aktor (Garin Nugroho) untuk beraksi dan bereaksi dengan cara-cara tertentu. Kedua, analisis arena yang merupakan dunia tempat melakukan permainan-permainan antara aktor dan agen/ struktur atau sering disebut dengan game. Ketiga, menganalisis modal yang memungkinkan seorang aktor mendapatkan kesempatan-kesempatan dalam kehidupan sosialnya. Keempat, menganalisis strategi yang diterapkan oleh aktor dalam melakukan pertukaran kapital yang dimiliki dan juga struktur modal dalam posisinya di lingkup sosial. Berdasarkan keterkaitan keempat elemen proses tersebut, kerangka kerja dalam penelitian ini dapat digambarkan pada gambar 1 .

\section{Hasil dan Pembahasan}

\section{Habitus}

Habitus berada di dalam pikiran aktor sedangkan arena berada di luar pikiran aktor (Bourdieu, 1990). Meskipun sebenarnya semua konsep Bourdieu tersebut saling berkaitan dan memengaruhi, habitus merujuk pada struktur mental atau kognitif, yang digunakan aktor untuk menghadapi ke-

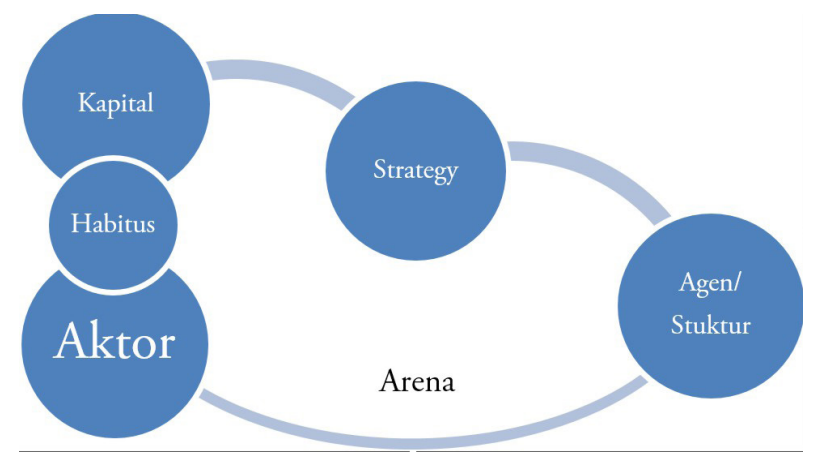

Gambar 1. Skema strukturalisme genetik Pierre Bourdieu 
hidupan sosialnya. Dengan kata lain habitus individu merupakan hasil sejarah pengalaman hidup seorang aktor, kemudian terinternalisasi dalam dirinya, kemudian digunakan untuk merasakan, memahami, menyadari, dan menilai dunia sosialnya (Ritzer \& Goodman J., 2003: 522). Melalui pola-pola itulah seorang individu memproduksi tindakan aktor dan juga menilainya, dalam hal ini habitus mengendalikan pikiran dan pilihan tindakan individu. Habitus dapat digambarkan sebagai hasil atau produk dari internalisasi struktur dunia sosial yang diwujudkan. Habitus diperoleh sebagai akibat dari lamanya posisi dalam kehidupan sosial yang di duduki. Dengan demikian, habitus akan berbeda-beda, tergantung di mana dan bagaimana posisi individu tersebut dalam kehidupan sosial.

Dalam wawancara forum diskusi penyutradaraan film Indonesia (Indonesia Film Director Club) 2014, Garin Nugroho mengungkapkan bahwa dirinya selalu melakukan adaptasi terhadap perubahan zaman. Meskipun usianya sudah paruh baya (lebih dari 50 tahun), ia tetap merasa perlu untuk mengamati dan memahami orang-orang di sekitarnya. Karena menurutnya perubahan dan dinamika budaya begitu cepat berganti, misalnya setelah tahun 1985 ia mengalami masa transisi budaya baru ketika laju teknologi informasi mulai tidak bisa dikontrol dan budaya global mulai membayangi kehidupannya. Saat itu perkembangan teknologi berakibat pada matinya industri populer seperti matinya industri komik dan novel di Indonesia. Maka, sebagai kreator ia harus bertahan hidup dalam gelombang serangan global yang membuat dirinya seperti anak kecil yang selalu terkaget-kaget karena semua hal menjadi serba baru dalam waktu singkat.

Nama Garin Nugroho mulai dikenal luas setelah film cerita panjang pertamanya, Cinta dalam Sepotong Roti (1990) mendapat sambutan hangat dari masyarakat Indonesia dan insan perfilman dengan berbagai macam penghargaan baik dalam skala nasional maupun internasional antara lain: (1) Piala Citra Festival Film Indonesia (FFI) 1991 untuk kategori film, artistik, editing, musik, dan fotografi terbaik; (2) Penghargaan Festival Film Asia Pasific (FFAP) 1992 (Seoul) untuk kategori sutradara pendatang baru; (3) Piala H Antemas,
FFI 1992, untuk film unggulan terlaris 1991-1992; (4) Unggulan FFI 1991 untuk kategori sutradara, cerita, dan suara.

Tahun 1991 Garin Nugroho mendapat kesempatan mengunjungi Amerika Serikat untuk melihat perkembangan dunia sinema. Garin Nugroho mendapat informasi bahwa pada masa depan akting hanya menjadi sebuah imajinasi karena semuanya akan menggunakan teknologi green screen. Pengalaman tersebut kemudian menjadi bahan internalisasi dalam diri Garin Nugroho. Ia merasa perlu mencari cara lain agar sebagai sineas Indonesia, ia tetap dapat bersaing di dunia global. Dialektika internalisasi yang dialami Garin Nugroho menuntunnya untuk berani menutup luka lama dan membuka luka baru di setiap transisi budaya global. Garin Nugroho mengungkapkan bahwa:

Siapa saya dan bagaimana saya mengalami teori-teori baru, misalnya teori hibriditas harus mampu saya definisikan ulang. Dari sini kemudian saya mulai mencoba-coba metode yang berbeda atau teori lain untuk bercerita menggunakan medium film. Karena kalau saya tidak suka coba-coba saya bisa tertidur dalam berkarya (Wawancara, 2016).

Dialektika internalisasi Garin Nugroho nampak dalam karya film keduanya, Surat untuk Bidadari (1992). Sebuah gaya film yang mengungkap karut-marut budaya Indonesia yang diwakili oleh sebuah desa kecil di Sumbawa. Gaya tutur yang disajikan dalam film ini menggunakan sodoran-sodoran masalah (Kristanto, 2005). Film ini sempat menimbulkan kontroversi karena gaya bertuturnya. Ada yang menganggap bagian dari alam post-modernisme, ada yang mengatakan film ini setengah fiksi dan setengah dokumenter. Karena kesulitan dalam peredaran, akhirnya Senakki (Serikat Nasional Kine Klub Indonesia) mengelilingkannya ke lima universitas di Jakarta untuk didiskusikan pada Juni-Juli 1994. Hingga saat ini, walaupun film tersebut belum beredar secara umum di bioskop Indonesia, film ini berhasil membawa Garin Nugroho ke dunia panggung film internasional. Sejak saat itu ia mulai merambah ke berbagai festival film internasional, antara lain: (1) 
Penghargaan dari Berliner Zeitung dalam forum Des Jungen Film, Festival Film Berlin 1994 karena potret otentik tentang kehidupan masyarakat yang tumbuh di tengah tradisi dan modernitas; (2) Gold Prize Young Competition, Festival Film Internasional Tokyo 1994; (3) Film terbaik, Festival Film Toarmina, Italia 1994; (4) Piala Cariddi d'Oro, Festival Film Internasional Toarmina XXIV, 1994 untuk film terbaik; (5) Pemenang seleksi kompetisi Young Cinema Festival Film International Tokyo 1994; (6) Penghargaan majalah sastra dan budaya Horizon tahun 1994 untuk pendekatan baru yang berani dan menyegarkan dalam sebuah film.

\section{Arena}

Arena adalah sepotong kecil dunia sosial, sebuah dunia penuh kesepakatan yang bekerja secara otonom dengan hukum-hukumnya sendiri (Binawan, 2007). Bourdieu melihat arena sebagai sebuah arena pertarungan dan juga lingkungan perjuangan, arena adu kekuatan, sebuah medan dominasi dan konflik antarindividu, antarkelompok demi mendapatkan posisinya. Posisi-posisi ini ditentukan oleh banyaknya kapital atau modal yang mereka miliki. Semakin banyak jumlah dan jenis modal yang mereka miliki, ia akan mendapatkan posisi terbaik dalam arena tersebut atau menduduki posisi yang dominan dalam suatu arena.

Hubungan antara seni dan teknologi menjadi arena perjuangan yang dipilih Garin Nugroho untuk memperjuangkan kreativitasnya melalui medium film. Sebagai sineas, Garin Nugroho menyadari bahwa kemajuan teknologi media rekam saat ini telah memberikan banyak kemudahan dalam proses membuat film. Baginya menciptakan sebuah karya film bukan hanya soal kualitatif karena perjalanan seni dan teknologi dalam pertarungan dunia global telah berubah menjadi idealisme individu. Akan tetapi, persoalannya adalah siapa yang mampu melahirkan ekspresi-ekspresi dari wacana-wacana globalisasi menjadi sesuatu atau sebuah karya yang dapat mengikuti pertarungan-pertarungan kreativitas tingkat dunia.

Arena perjuangan Garin Nugroho dimulai dengan membangun komunitas Sains Estetika dan Teknologi (SET). SET didirikan sebagai respons dari munculnya arus baru demokratisasi di Indone- sia yang menuntut peran dan hubungan baru antara masyarakat, teknologi, media, budaya, politik, dan tanggung jawab sosial korporasi. Pada tahun 1999 SET meneguhkan peran publiknya sebagai produser pelaksana karya-karya sosialisasi Pemilu 1999 yang memotret keragaman suku bangsa. Kemudian SET memperluas perannya dengan turut serta mendorong tumbuhnya demokratisasi media lewat serangkaian program perkembangan multidisiplin (seni, teknologi, dan sains).

Arena adalah sejenis pasar kompetisi berbagai jenis modal (ekonomi, kultur, sosial, simbolik) digunakan dan disebarkan. Arena merupakan lingkungan kekuasaan (politik) yang sangat penting bagi habitus seseorang (Ritzer \& Goodman J., 2003: 523-524). Dalam sebuah arena terjadi dialektika hubungan antara struktur subjektif dan struktur objektif yang merupakan dimensi pertama habitus yang terdiri dari dimensi praksiologis (arah orientasi sosial) dan dimensi afeksi (citacita, selera). Dua dimensi habitus ini melukiskan adanya disposisi seseorang atau suatu kelas sosial dalam menentukan arah orientasi sosial, cita-cita, selera, cara berpikir, dan etos kerja (motivasi). Disposisi itu adalah kecenderungan sikap dalam mempersepsi, merasakan, melakukan, dan berpikir, yang diorientasikan oleh individu berkat kondisi objektif eksistensi seseorang. Kemudian disposisi itu berfungsi sebagai prinsip tidak sadar atas tindakan, persepsi, dan refleksi yang dilakukan dengan spontan. Jadi, disposisi yang sudah diperoleh akan mengondisikan perolehan lebih jauh disposisi-disposi lain dalam sebuah arena perjuangan. Bourdieu menjelaskan bahwa hubungan antara arena dengan habitus adalah relasionisme metodologis, yakni sebuah hubungan timbal balik antara lingkungan dengan habitus. Di satu pihak lingkungan mengondisikan habitus, di pihak lain habitus menyusun lingkungan, sebagai sesuatu yang bermakna atau yang mempunyai arti dan nilai (Haryatmoko, 2010). Demikian halnya dengan hubungan antara arena dan habitus yang dimiliki Garin Nugroho sebagai sineas.

\section{Kapital}

Kapital atau modal merupakan aset yang dimiliki individu dalam lingkungan sosialnya 
yang digunakan untuk menentukan posisi dalam suatu ranah. Kapital itu harus selalu diproduksi dan direproduksi kembali. Menurut Bourdieu terdapat empat jenis kapital, yaitu kapital ekonomi, kapital sosial, kapital kultural, dan kapital simbolik (Binawan, 2007). (1) Kapital ekonomi adalah segala bentuk modal yang dimiliki aktor yang berupa materi, misalnya uang, emas, mobil, dan tanah. Dalam proses pembuatan film setiap kru memiliki kualifikasi kemampuan dan tanggung jawab tertentu dalam pembagian kerja sehingga semakin tinggi jabatan fungsional yang dimiliki seorang dalm proses produksi tersebut, semakin tinggi pula komisi yang diperolehnya. (2) Kapital sosial, terdiri dari hubungan sosial yang bernilai antara individu, atau hubungan-hubungan dan jaringan hubungan-hubungan yang merupakan sumber daya yang berguna dalam penentuan dan reproduksi kedudukan-kedudukan sosial. Film adalah sebuah karya kolaboratif dari banyak elemen pendukungnya, namun kepemilikan sebuah karya film cenderung disandarkan pada seorang sutradara. Hal ini dapat dijelaskan karena seorang sutradara film memiliki kapital sosial dalam menghubungkan dan memimpin krunya dalam proses kolaborasi dan mengkonversi unsur-unsur abstak konsep skenario menjadi medium audiovisual yang lebih konkret. (3) Kapital kultural, meliputi berbagai pengetahuan yang sah, misalnya ijazah pendidikan formal. Kapital kultural yang dimiliki Garin Nugroho adalah tanda kelulusan pendidikannya, berupa ijazah atau tanda kelulusan dari Fakultas Sinematografi, IKJ dan Fakultas Hukum, Universitas Indonesia. (4) Kapital simbolik, berasal dari kehormatan dan prestise seseorang. Gelar sutradara terbaik atau penghargaan film terbaik dari berbagai festival film baik dalam negeri maupun luar negeri menjadi modal simbolik yang dimiliki oleh Garin Nugroho. Dengan modal/kapital simbolik ini, ia dapat lebih mudah melakukan pertukaran modal dalam struktur sosialnya.

\section{Strategi}

Dunia sosial digambarkan Bourdieu dalam bentuk ruang dengan beberapa dimensi yang dipengaruhi oleh prinsip diferensiasi dan distribusi. Para aktor menempati posisi masing-masing yang ditentukan oleh dua dimensi: pertama, menurut besarnya modal yang dimiliki, dan kedua sesuai dengan bobot komposisi keseluruhan modal mereka (Haryatmoko, 2010). Dengan demikian, setiap orang atau kelompok akan berusaha mempertahankan dan memperbaiki posisinya, membedakan diri dan mendapatkan posisiposisi baru. Perjuangan, ketegangan, dan konflik juga terjadi pada tingkat kelembagaan untuk memperoleh kedudukan dan posisi tertentu. Akan tetapi, perjuangan untuk memperebutkan posisi dan pengelompokan ini mengandaikan suatu pertarungan sosial juga dalam ranah simbolis.

Dalam ranah perjuangannya, Garin Nugroho memiliki keyakinan bahwa era transisi teknologi menjadi medan kompetisi kreativitas. Revolusi teknologi informasi semakin dipercepat dengan waktu pendek. Hal tersebut berdampak pada dunia bisnis film yang makin cepat berkembang. Dilemanya adalah akan terjadi apa yang disebut pengklasikan yang terlalu cepat. Cara-cara lama akan menjadi klasik, keterkenalan atau kepopuleran menyebar dengan cara yang luar biasa, sementara yang alternatif mengelola perpaduan antara pengklasikan dan kepopuleran.

Keyakinan atau believe adalah sesuatu yang dipegang oleh aktor yang memiliki nilai atau dianggap bernilai. Peran suatu keyakinan adalah sebagai dasar untuk melakukan tindakan atau praktek dalam suatu ranah. Keyakinan yang dipegang oleh Garin Nugroho adalah konsisten dalam memilih teknologi sebagai alat bantu dalam mewujudkan kreativitas. Hal tersebut ia ungkapkan ketika menjawab pertanyaan strategi kreatif menghadapi era digital

Saya akan tetap memegang cara-cara lama dalam membuat film, meskipun era sudah globalisasi sebenarnya tidak akan menjadi masalah. Misalnya, film hitam-putih dengan cara-cara lama tetap hidup meskipun berada dalam era digital (Wawancara, 2016).

Setidaknya terdapat dua strategi yang terarah langsung dalam hubungan dengan perjuangan dalam lingkup sosial, yaitu strategi investasi ekonomi dan strategi investasi simbolis. Strategi investasi ekonomi merupakan upaya untuk 
mempertahankan atau menambah modal dari berbagai jenisnya. Jadi, bukan hanya modal ekonomi yang dicari melainkan juga modal sosial yang dimanfaatkan untuk melanggengkan hubungan-hubungan sosial yang dapat berguna baik dalam jangka pendek maupun jangka panjang. Hubungan-hubungan sosial itu agar terpelihara kemudian dijadikan kewajiban yang berkelanjutan dalam bentuk pertukaran uang, kerja sama, menyediakan waktu, dan sebagainaya. Adapun strategi investasi simbolik adalah upaya untuk mempertahankan atau meningkatkan adanya pengakuan sosial. Stategi ini bertujuan untuk memproduksi persepsi dan penilaian yang mendukung kekhasan atau gaya seorang sineas dalam membuat film (Haryatmoko, 2010).

Garin Nugroho tidak pernah memikirkan cara menjual karyanya di bioskop agar mendapat banyak penonton. Ia memikirkan bagaimana karyanya mendapatkan sumber dana. Dalam hal ini stategi ekonomi yang digunakan Garin Nugroho adalah kesesuaian segmentasi penonton dengan filmnya bukan film yang justru mencari penonton. Dengan demikian, kejelasan siapa penonton film yang ia buat harus jelas terlebih dahulu, baru kemudian ia akan menghubungkan penonton itu dengan pemodalnya. Hal ini ia lakukan karena masih kurangnya apresiasi seni di Indonesia, yaitu trend film bioskop terkadang menjatuhkan pasar tanpa etika. Maka untuk terus berlari ke depan terkadang seorang sineas juga perlu menghayati perasaan tertinggal sebagai hal yang romantis untuk menciptakan sebuah karya film.

Strategi tersebut mulai terlihat dalam proyekproyek film Garin Nugroho berikut pada tahun 2000. Sebagai contoh, Garin Nugroho mampu bekerja-sama dengan sekian banyak maestro seni, mulai dari seni vokal dan musik Jawa (tembang dan karawitan), seni kostum, seni tari, sampai dengan seni rupa kontemporer, khususnya seni instalasi dalam menghasilkan film Opera Jawa (2006) (Budiman, 2013). Contoh lain, proyek film yang berjudul Generasi Biru (2009) selain bertindak sebagai sutradara dan penulis skenario Garin Nugroho mulai merambah posisi sebagai produser eksekutif (pemodal). Proyek film yang berjudul Mata Tertutup (2011) dan Isyarat (2013) dikerjakan oleh Garin Nugroho secara independen. Dalam proyek film The Mirror Never Life (2011) ia hanya bertindak sebagai produser yang menghubungkan WHO dan organisasi terkait dalam mewujudkan karya film yang bertemakan lingkungan biota laut di Pulau Wakatobi. Selain itu, dalam mewujudkan sebuah karya film, ia juga menjalin kerja sama dengan lembaga atau badan milik swasta maupun pemerintah, misalnya proyek film Soegija (2012) dan Guru Bangsa Cokroaminoto (2015), film Ach... Aku Jatuh Cinta (2015) bersama Rumah Produksi MVP Pictures.

\section{Simpulan}

Berdasarkan pembahasan tersebut dapat disimpulkan bahwa habitus dapat digambarkan sebagai hasil atau produk dari internalisasi struktur dunia sosial yang diwujudkan. Dialektika internalisasi dialami Garin Nugroho sehingga menuntunnya untuk berani menutup luka lama dan membuka luka baru di setiap transisi budaya global. Dengan demikian, Garin Nugroho berupaya mendefinisikan ulang pengalaman-pengalaman sosialnya, kemudian menerapkan hasil internalisasi tersebut dalam memproduksi karya-karya filmnya. Selain itu, Garin Nugroho juga terus melakukan eksperimen dalam menggunakan teknologi film sebagai medium untuk bercerita.

Hubungan antara seni dan teknologi menjadi arena yang dipilih Garin Nugroho untuk memperjuangkan kreatiitasnya melalui medium film. Sebagai sineas, Garin Nugroho menyadari bahwa kemajuan teknologi media rekam saat ini telah memberikan banyak kemudahan dalam proses membuat film, namun mewujudkan sebuah karya film bukan saja hal yang kualitatif. Hal ini karena dalam perjalanannya seni dan teknologi menuntun seorang sineas untuk memiliki idealisme individu. Garin Nugroho memulai perjuangannya dengan membangun komunitas Sains Estetika Teknologi (SET) Film Workshop sebagai arena perjuangan. Dari arena perjuangan itu, Garin Nugroho memiliki beberapa jenis modal/kapital, antara lain: (a) Kapital ekonomi, berupa materi dari komisi sebagai produser, sutradara, dan penulis skenario; (b) Kapital sosial, berupa kepercayaan masyarakat 
sebagai seorang sineas yang berkualitas dengan bukti beberapa penghargaan dari festival-festival film nasional dan internasional; (c) Kapital kultural, berupa tanda kelulusan pendidikannya, yakni ijazah atau tanda kelulusan dari fakultas sinematografi, Institut Kesenian Jakarta dan Fakultas Hukum, Universitas Indonesia; (d) Kapital simbolik, berupa gelar sutradara terbaik atau penghargaan film terbaik dari berbagai festival film baik di dalam maupun di luar negeri. Dengan modal/kapital simbolik ini, ia dapat lebih mudah melakukan pertukaran kapital dalam struktur sosialnya.

Dalam ranah perjuanganya, Garin Nugroho memiliki keyakinan bahwa era transisi teknologi menjadi arena kompetisi kreativitas sehingga ia tetap konsisten dalam memilih teknologi sebagai alat bantu dalam mewujudkan sebuah karya film. Hal ini kemudian menjadi strategi kreatifnya untuk menghadapi era digital. Meskipun dalam realitas masyarakat umum, modal ekonomi dan modal kultural cenderung menggantikan kekuasaan langsung terhadap individu. Dalam dunia seni, modal sosial dan modal simbolik lebih dihargai daripada bentuk modal yang lain. Hal ini kemudian menjadi strategi Garin Nugroho untuk mendapatkan sumber dana dalam memproduksi karya filmnya.

\section{Ucapan Terima Kasih}

Penulis mengucapkan terima kasih kepada Forum Indonesian Film Directors Club (IFDC) yang telah memberikan kemudahan kepada peneliti untuk mendapatkan informasi tentang topik penulisan artikel ini.

\section{Kepustakaan}

Binawan, Al. E. (2007). "Habitus Nyampah: Sebuah Refleksi”. Basis, Vol 56 No. 05/07 Mei
Bourdieu, P. (1990). The Logic of Practice. California: Atanford University Press.

Budiman, C. (2013). Retorik dan Makna Ideologis Karya Instalasi dalam Film Opera Jawa Garin Nugroho. RESITAL : JURNAL SENI PERTUNJUKAN, 14(1). doi:http://dx.doi. org/10.24821/resital.v14i1.390

Haryatmoko. (2010). Habitus dan Kapital Dalam Strategi Kekuasaan, teori strukturasi Pierre Bourdieu dengan Orientasi Budaya. Jakarta: Pasca Sarjana Sosiologi Universitas Indonesia. Kristanto, J. B. (2005). Katalog Film Indonesia 1926-2005. Jakarta: Nalar.

Laksono, K; Purba, SA \& Hapsari, PD. (2015). Musik Hip-Hop sebagai Bentuk Hybrid Culture dalam Tinjauan Estetika. RESITAL: JURNAL SENI PERTUNJUKAN, 16(2). doi:http://dx.doi.org/10.24821/resital. v16i2.1507

Prasetya, H. B., Haryono, T., \& Simatupang, L. L. (2016). Habitus, Ngêng, dan Estetika Bunyi Mlèsèt dan Nggandhul pada Karawitan. Paradigma, Jurnal Kajian Budaya, 1(2), 152-167.

Ritzer, G., \& Goodman J., D. (2003). Teori Sosiologi Modern. Jakarta: Prenada Media.

Tino, S. (2008). Dongeng Sebuah Produksi Film. Jakarta: Intisari Mediatama.

\section{Web}

www.set-film.com diakses tanggal 17 November 2015.

www.filmindonesia.or.id diakses tanggal 17

November 2015.

www.youtobe.com : IFDC AWARDS 2014

Seri Diskusi_Sutradara Film Indonesia Hari

Ini (22 November 2014) diakses tanggal 10

November 2015. 